\title{
Strategic Consumer Behavior Analysis Based on Dual Channels and Sale Periods
}

\author{
Guojun Ji and Yang Zhao* \\ School of Management, Xiamen University, 361005 Fujian, China \\ zyk400sxdy@163.com
}

\begin{abstract}
The dual channels increase the conflict between manufacturers and retailers, but offer customers more alternatives. Strategic customers can choose both sale channels and sale periods. The dual channels include the manufacturer's electronic channel and the retail channel. The sale periods divide into normal and discount sale periods. Based on dual channels and different sale periods, we identify six different kinds of strategic customer choices based on the relationships among the related parameters. The results also show that when WTP is near its maximum the best choice is to buy during the normal sale period via the retail channel. Then we discuss how manufacturers and retailers price product in different types of strategic customer choices, and find the discount price to be higher than the normal price under the single game condition. The conclusions can both support strategic customers in making purchase decisions, and can also help manufacturers and retailers mitigate the influence of strategic behaviors.
\end{abstract}

Keywords: Strategic customers, Dual channels, Sale periods, Willingness to pay (WTP)

\section{Introduction}

E-commerce growth is driving firms to establish direct sales channels online. Ecommerce provides an efficient trade channel, and many firms can communicate more quickly with customers, realize online sales, and improve customer relationships through electronic channels [1]. From the perspective of customers, e-commerce caters to the desire to shop at home, and offers enormous convenience. Online shopping has become a fashion and trend [2]. In China, according to the "28th China Internet Development Statistics Report" and "2010 China online shopping market research report" released by the China Internet Network Information Center (CNNIC), online transactions totaled $¥ 523$ billion in 2010 , increased $9.2 \%$ from 2009 . Meanwhile the online shopping market has become more important in the consumer goods market. Electronic channels accounted for $1.1 \%$ of the transaction value of total retail sales of social consumer goods in 2008, increasing to $2 \%$ in 2009 and $3.3 \%$ in 2010, indicating that electronic channels have become a new profit growth point.

More and more manufacturers are selling products via electronic channels to increase their market competitiveness. According to a report from The New York Times, about $42 \%$ of high-end manufacturers sell their products through electronic channels in addition to conventional retail channels, including IBM, Estee Lauder and Nike [3]. In China, Haier Group integrates its own electronic channel with retail channels. However, while such use of dual channels increases manufacturer profits, it also aggravates the conflict between retailers and manufacturers. Levi Strauss thus ceased its use of electronic channels to avoid dual channel conflict [4].

Manufacturers can use dual channels to sell products, and department stores and retail industries also cut prices to grab customers from manufacturers. Sales strategies based on dual channels and sale periods train customers to be rational. Customers thus adopt 
strategic behavior whereby they wait for the lowest possible discount price before making a purchase. Various industries thus have become flooded with strategic customers. For example, random surveys of retail customers conducted during holiday periods found that strategic waiting means customers face enormous psychological pressure from the possibility of product unavailability, but more than $50 \%$ of customers still prefer to wait to purchase at the last minute owing to the increased utility. Notably, in the clothing industry, strategic customer behavior means about $50 \%$ of inventory is sold at discount prices [5]. Purchasers of automobiles, home appliances and other durable goods also routinely wait for prices to fall before they purchase. The aviation industry also exhibits strategic waiting behavior, as tourists often delay travel plans until lowest cost becomes available [6]. Additionally, a recent survey found that ignoring strategic customer behavior resulted in a $30 \%$ loss of profits in the video game industry [7]. Strategic customers can choose to buy product from electronic or retail channels, and during normal or discounted sale periods. Manufacturers therefore must focus on strategic customer behavior.

In this paper, we seek to understand the different choices of strategic customers in different conditions, and how manufacturers and retailers set prices in the face of each type of strategic customer choice. To answer these questions, we review the related literature and introduce our research method as follows.

\section{Literature Review}

Based on the dual channels and sale periods, our research focuses on how strategic customers buy products, and how manufacturers and retailers respond to reduce strategic customer influence on price. The literature on this area can be categorized by focus as follows: (1) dual channels and sale periods, (2) strategic customers.

The development of the Internet and e-commerce provides a new distribution model for manufacturers. In addition to using retail channels, manufacturers can use electronic channel to sell products to customers directly. The use of dual channels always improves manufacturer profits relative to using electronic channel only, and under certain conditions is superior to using retail channel only. In particular, this arrangement gives the manufacturer more room to bargain with retailers [8]. The profits of manufacturers and retailers depend on cost structure and benchmark market share, and the use of dual channels enables manufacturers to increase demand and thus their own profits, and to enhance overall supply chain performance and social welfare, while damaging retailer profits and thus causing channel conflict [9]. Chiang, et al., and Arya, et al., analyzed the impact of electronic channels on the profits of supply chain members based on consumer differences, and pointed out that it is imperative for manufacturers to open electronic channel, since this can increase profits even if the channel itself does not generate sales [3, 10]. Manufacturers thus can adopt electronic channel as a strategic measure to increase overall channel effectiveness. Some scholars have researched the relationship between the use of dual channels and service level. Yao, et al., and Yan, et al., indicated that retail channel service level influences market demand for dual channels, and the introduction of electronic channel can improve retail service level $[11,12]$. Chun, et al., found that manufacturers still choose a single retail channel when consumers are strongly heterogeneous or the retailer provides a higher level of service [13]. The above demonstrates that many factors affect whether a manufacturer sets up an electronic channel to form dual channel distribution, such as market demand, consumer acceptance of electronic channels, retail channel service level and so on. Under certain conditions, manufacturer adoption of dual channel distribution can increase profits.

For retailers, manufacturers that open up electronic channel inevitably become competitors. Although dual channels can expand the market, they also intensify market competition. Chiang, et al., and Cai verified that electronic channel are bad for retailers [3, 
8]. Therefore, manufacturers setting up electronic channel must consider the potential for channel conflict and aim to avoid damaging their good long-term partnerships with retailers. As the rapid development of e-commerce has made it more common for manufacturers to set up electronic channel, more scholars have discussed dual channels from the perspective of manufacturers. From the background of uniform pricing, Tsay, et al., discussed how a dual-channel service strategy could optimize benefits for both manufacturers and retailers, and showed that dual channels can increase retailer profits, and in some case the profits of both manufacturers and retailers [14]. Zettelmeyer found that electronic channel lowers wholesale prices, and that retailers can profit by adopting appropriate pricing strategies [15]. Cattain, et al., considered that retailers should see manufacturer's electronic channel as a form of market segmentation that does not damage their interests and can increase profits [16]. Mukhopadhyay, et al., proposed that retailers can avoid channel conflict through value-added services that differentiate their offerings from products offered via electronic channel, thus resulting in channel diversity [17]. Yan, et al., studied a traditional retailer using retail channel and an online retailer using electronic channels, and found that forecast accuracy affected the performance of the traditional retailer more than that of the online retailer [18]. Xing, et al., found that channel positively impacts the equilibrium strategy of manufacturers and retailers, and can decrease conflicts between them [19]. Chen, et al., concluded that manufacturer contracts that differentiate wholesale and direct channel prices can coordinate dualchannel supply, and benefit retailers but not manufacturers [20].

Strategic customer behavior can influence firm decision making, and this phenomenon has been confirmed in retail channel [21, 22]. Cachon, et al., classified customers into three categories: short-sighted customers who choose to buy at normal prices; strategic customers who purchase during appropriate sale periods; and bargain-seeking customers who only purchase at a discount. This study finds that strategic customers can increase retailer profits. Firms should use a strategy of dynamically reducing prices, even if it involves following the price evolution path [23]. Based on the above conclusions, Lai, et al., investigated the price matching strategy, which eliminates the enthusiasm of customers to delay buying, thus allowing retailers to increase prices during normal sale periods. This strategy was found detrimental for retailers when the proportion of strategic customers in the market is low or the WTP of strategic customer changes significantly over time [24]. Su and Zhang included strategic customers in the newsvendor model and arrived at the rational expectations equilibrium model of retailers. They proposed that inventory level in equilibrium is lower than in the newsvendor model without strategic customers, and further proposed using quantity and price commitments to increase retailer profits [25]. Su and Zhang further considered shortages and concluded that manufacturer commitments to customers mitigate the effect of strategic customers on their profits [26]. Aviv and Pazgal discussed seasonal merchandise sales under limited inventory, and found customer valuations of merchandise decrease over time. For strategic customers, they demonstrated the existence of subgame perfect equilibrium under both fixed and temporary discounts [27]. Cachon and Swinney analyzed three different retailer systems: rapid replenishment system, strengthening design system and traditional systems, and found that the rapid replenishment and strengthening design systems can alleviate the delayed buying behavior of strategic customers in different ways, and thus both complementary and alternative, though primarily the former [28]. Su studied the dynamic pricing model with speculators and strategic customers, and showed that although speculators can increase retailer profits, they also encourage retailers to limit production capacity and hence reduce their capacity investment [29]. Liu, et al., applied the Stackelberg game model and mechanism design theory to research how strategic customer behavior affects retailer inventory and pricing, and found that increasing the risk of rationing can reduce waiting behavior [30]. Ji, et al., introduced pre-sale and post-sale 
heterogeneity of maximum WTP, and found that given pre-sale heterogeneity, creating price risk can encourage strategic customers to purchase early, while given post-sale heterogeneity, creating rationing risk can induce strategic customers to purchase in advance [31]. Jerath, et al., found that opaque selling better mitigates strategic customer behaviors than direct last-minute selling, and makes firms can require higher demand [32]. Liu, et al., considered dynamic pricing competition between two firms offering differentiated products, and showed that both suffer decreased profits as they rely increasingly on strategic customers, but the low-quality firm suffers more than the highquality firm [33].

Most of the previous literature discusses strategic customer behavior in traditional retail channel, and few studies have considered strategic customers in the context of dual channels. The electronic channel reduces search costs, and allows strategic customers to easily compare price, which also contributes to strategic customer behavior. Strategic customers thus inevitably affect dual channel supply chains. Based on the extant literature, this paper analyzes strategic customer behavior in the context of dual channels and different sale periods. When the manufacturer and retailer set different prices, strategic customers react and select their buying patterns according to expectation maximization. Facing each type of strategic customer choice, the manufacturer and retailer price to realize benefit maximization in the Stackelberg model. This study then applies numerical analysis to analyze how the parameters affect the optimum strategy. The conclusions of this study provide theoretical and methodological support for strategic customer behaviors, and also help the manufacturer and retailer better understand the strategic choices. The model is detailed below.

\section{The Model}

Our model includes one manufacturer, one retailer and strategic customers. The manufacturer has two distribution channels: one involves selling products online, i.e., the electronic channel, and is represented by $N$; the other involves selling via retailers, i.e., the retail channel, and is represented by $S$. We call this the dual channel distribution model. $M$ expresses the manufacturer, and $R$ expresses the retailer. The dual channels are shown in Figure 1.

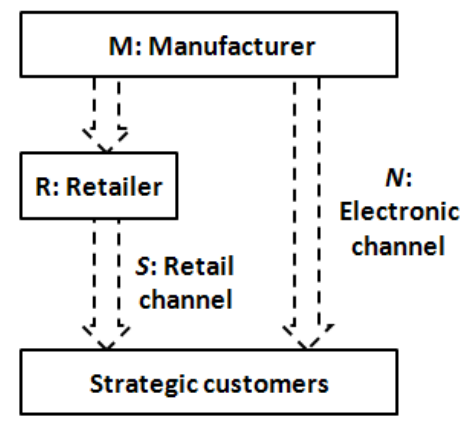

Figure 1. Dual Channels

Product sales are divided into two periods: sales during the first period are at normal price, while sales during the second period are discounted. We use $1 S$ to express normal price sales via the retail channel, $1 N$ to express normal price sales via the electronic channel, $2 S$ to express discounted sales via the retail channel, and $2 N$ to express discounted sales via the electronic channel. The manufacturer first decides the wholesale price $\mathrm{W}$, then in the first sale period, the manufacturer determines the electronic channel price $P_{1 N}$ before the retailer decides the retail channel price $P_{1 S}$, after which strategic customers choose to either buy or wait. The second sale period resembles the first, and the 
manufacturer decides the price $P_{2 N}$, the retailer then decides the price $P_{2 S}$, and strategic customers purchase via either the retail or electronic channel. Strategic customers not only choose sale periods to make their purchase, but can also choose the channels through which they do so. The decision-making process is shown in Figure 2.

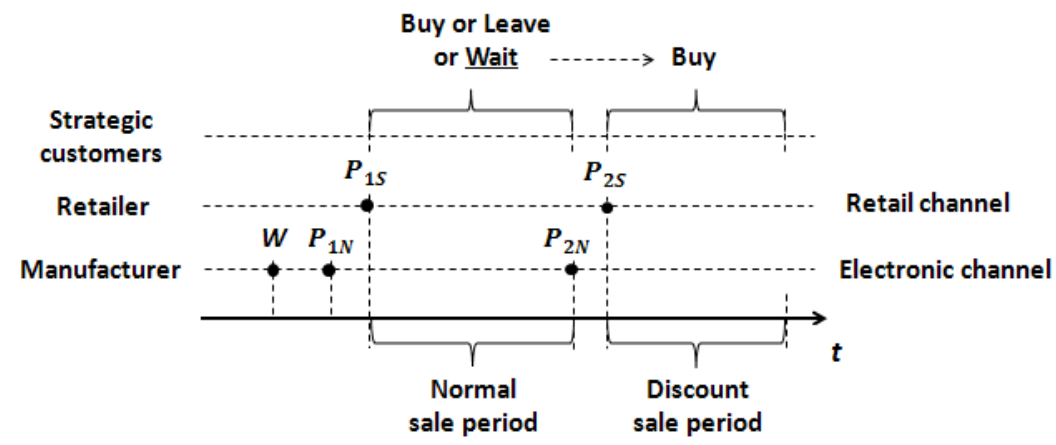

Figure 2. Decision-making Process

\subsection{Strategic Customers}

In this part, the product sale prices set by the manufacturer and retailer are exogenous variables. Meanwhile, the production costs of the manufacturer are $\bar{C}$, which is a constant. WTP of strategic customers is represented by $x \in[0, \bar{X}]$, which is a random variable. The population of strategic consumers is $q$. The demand function is $q_{i j}=f(x)-P_{i j}$, where $i=1,2$ and $j=N, S$. In the retail channel, strategic customers do not worry about product quality. However, in the electronic channel, strategic customers may perceive lower price to be associated with increased quality risks, and so we assume that $\beta \in[0,1]$ represents the degree of decrease in WTP when strategic customers purchase via the electronic channel. The discount coefficient is indicated by $\delta$. Sale periods are short, i.e., just a few months, so WTP remains virtually unchanged and we suppose that $\delta=1$. The model contains several preconditions:

( i ) Strategic customers may either make a purchase, regardless of channel and sale period, or leave the market, where the latter action indicates they are not interested in the product.

(ii) The products sold via the electronic channel are the same as those sold via the retail channel, i.e., $x_{S}=x_{N}=x$, so $x$ is used to express WTP regardless of channel, not to differentiate the two channels.

(iii) Strategic customers learn from previous experience and can estimate the size of discounts offered by the manufacturer and retailer, so once they know the price during the normal sale period, they can forecast the discount price.

Strategic customers decide to either buy or wait according to their own utility functions. During the normal sale period, the utility function is $u_{1 S}(x)=x-P_{1 S}$ for purchase via the retail channel, and $u_{1 N}(x)=\beta x-P_{1 N}$ for purchase via the electronic channel. Strategic customers can also select to wait. Strategic customers who wait during the normal sale period must buy the product during the discount sale period. In the second period, the utility function is $u_{2 S}(x)=x-P_{2 S}$ for purchase via the retail channel, and $u_{2 N}(x)=\beta x-P_{2 N}$ for purchase via the electronic channel. In the retail channel, price change is expressed by $\Delta P_{S}=P_{1 S}-P_{2 S}$, while in the electronic channel it is expressed by $\Delta P_{N}=P_{1 N}-P_{2 N}$. Owing to the price reduction in the discount channel, $P_{1 S}$ is larger than $P_{2 S}$; similarly, $P_{1 N} \geq P_{2 N}$, i.e., $\Delta P_{S} \geq 0$ and $\Delta P_{N} \geq 0$. 


\subsection{Strategic Customer Behavior during the Normal Sale Period}

Strategic customers can choose to either buy from the retail or electronic channel, or wait to buy during the discount sale period. We suppose that $\mu \in(0,1)$ denotes their preference for purchasing via the electronic channel during the discount sale period. Therefore, the utility function of waiting is $E\left(u_{2}\right)=\mu u_{2 N}+(1-\mu) u_{2 S}=(1+\mu \beta-$ $\mu) x-(1-\mu) P_{2 S}-\mu P_{2 N}$. The selection function of strategic customers is $V=$ $\max \left\{u_{1 S}, u_{1 N}, E\left(u_{2}\right)\right\}$. During the first step, $u_{1 S}$ and $u_{1 N}$ are always non-negative, so $x \geq \max \left\{P_{1 S}, P_{1 N} / \beta\right\}$.

If $P_{1 S} \geq P_{1 N} / \beta$, then $x \geq P_{1 S}$. When strategic customers choose to buy via the retail channel, then it should be the case that $u_{1 S} \geq u_{1 N}$, and we can deduce that $x \geq$ $\left(P_{1 S}-P_{1 N}\right) /(1-\beta)$. Comparing $u_{1 S}$ and $E\left(u_{2}\right)$ demonstrates that for customers who select the retail channel, the utility function should be such that $u_{1 S} \geq E\left(u_{2}\right)$, and thus $x \geq\left(P_{1 S}-(1-\mu) P_{2 S}-\mu P_{2 N}\right) /(\mu(1-\beta))$. Finally, comparing $u_{1 N}$ and $E\left(u_{2}\right)$ demonstrates that when strategic customers decide to wait, the utility function should meet the criteria $u_{1 N} \leq E\left(u_{2}\right)$, and it should then be the case that $x \geq\left((1-\mu) P_{2 S}+\mu P_{2 N}-P_{1 N}\right) /((1-\mu)(1-\beta))$. Suppose the following several equations:

$$
a=P_{1 S}, \quad b=\frac{P_{1 N}}{\beta}, c=\frac{P_{1 S}-P_{1 N}}{1-\beta}, d=\frac{P_{1 S}-(1-\mu) P_{2 S}-\mu P_{2 N}}{\mu(1-\beta)}, e=\frac{(1-\mu) P_{2 S}+\mu P_{2 N}-P_{1 N}}{(1-\mu)(1-\beta)}
$$

We can deduce several relationships given $P_{1 s} \geq P_{1 N} / \beta: a \leq c \leq d$ and $c \geq e$. According to the above analysis, when $e \leq a$, the choices of strategic customers during the normal sale period are illustrated by Figure 3 .

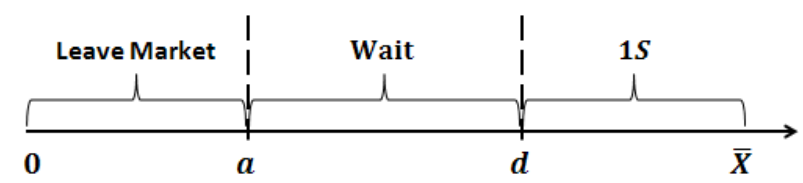

Figure 3. Choices of Strategic Customers in the Normal Sale Period

\subsection{Strategic Customer Behavior during the Discount Sale Period}

Waiting strategic customers can choose to buy the product via the retail or electronic channel during the discount sale period. If strategic customers choose the former, the utility function should meet the criteria $u_{2 S} \geq u_{2 N}$, i.e. $x \geq\left(P_{2 S}-P_{2 N}\right) /(1-\beta)$, and thus $f=\left(P_{2 S}-P_{2 N}\right) /(1-\beta)$. Comparative analysis easily obtains the relationship: $f \leq d$. Figure 4 shows the choices of strategic customers.

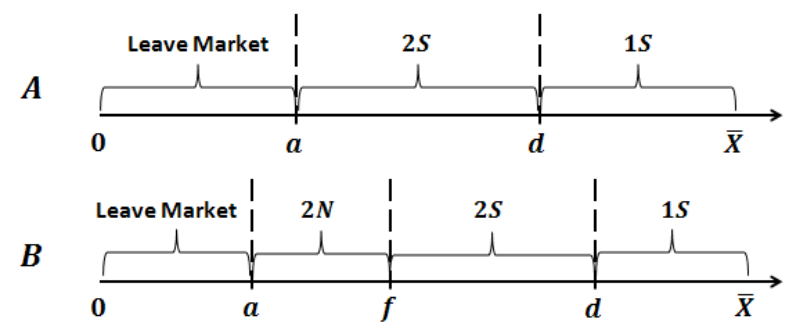

Figure 4. A Represents the Choices of Strategic Customers when $f \leq a B$ Represents the Choices of Strategic Customers when $f \geq a$

According to the class conditions, we can deduct the other four kinds of strategic customer choices illustrated by Table 1 . 
Table 1. The Six kinds of Strategic Customer Choices

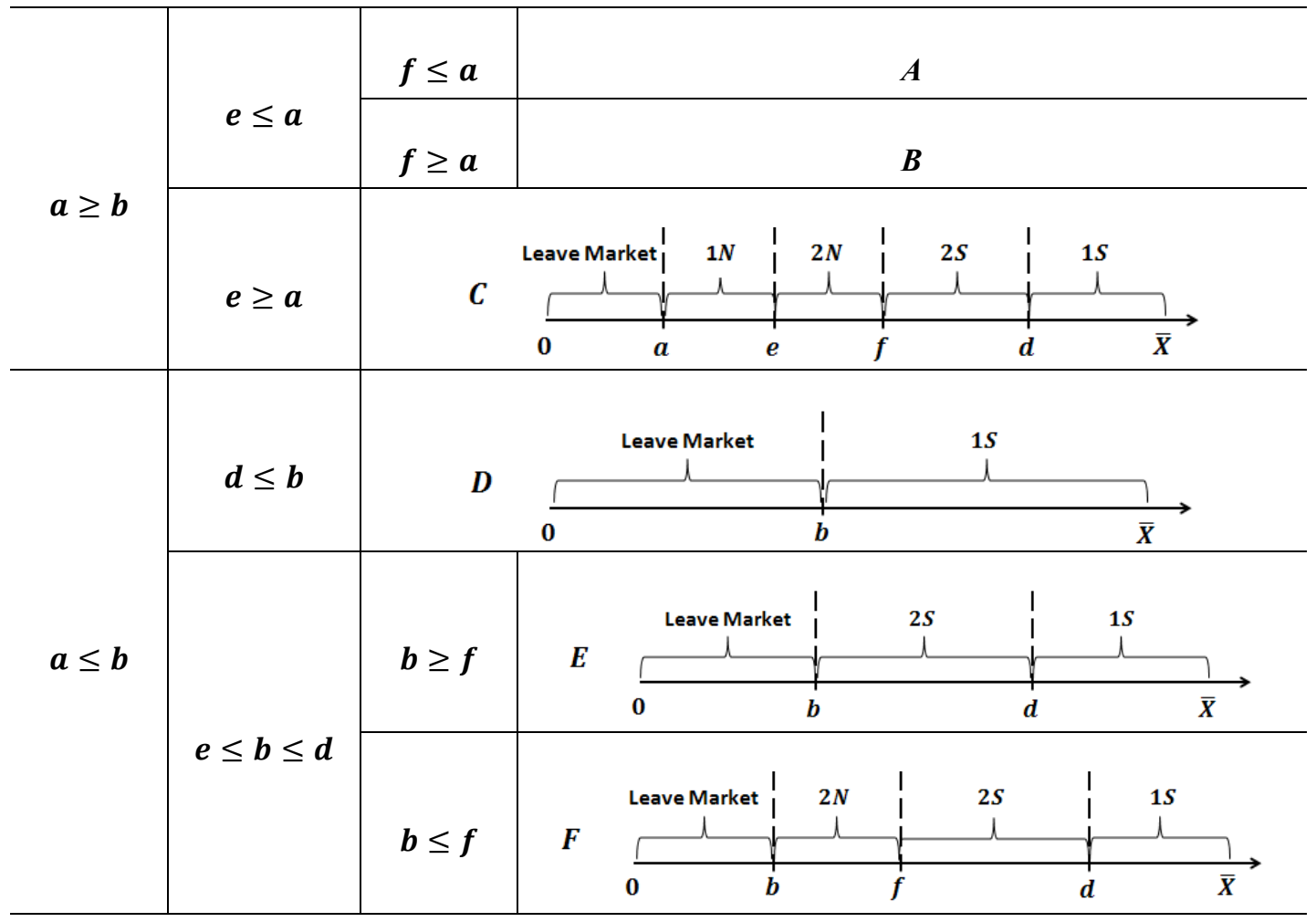

Lemma 1. When WTP nears zero, strategic customers will leave the market. When WTP is very high and close to $\bar{X}$, the best choice for strategic customers is to buy in the normal sale period via the retail channel.

Proof. From Table 1, we can conclude the following. When strategic customers have low WTP for a product, they may not be interested in the product and may take action to leave the market. Meanwhile, if strategic customers consider the product to have value and WTP approximates $\bar{X}$, they may purchase the product via the retail channel during the normal sale period.

Based on the relationship between $P_{1 S}$ and $P_{1 N} / \beta$, Figure 5 presents analysis of the six different kinds of strategic customer choices. The abscissa axis represents $\mathrm{P}_{1 \mathrm{~S}}$ and the vertical axis represents $P_{1 N} / \beta$. The straight line $P_{1 N} / \beta=P_{1 S}$ divides the first quadrant into two equal parts. Regions $A, B$ and $C$ are located in the lower part, while $D, E$ and $F$ occupy the upper part. A square is delineated by the abscissa axis, vertical axis, and the straight line $P_{1 S}=\left(P_{2 S}-P_{2 N}\right) /(1-\beta)$ and $P_{1 N} / \beta=\left(P_{2 S}-P_{2 N}\right) /(1-\beta)$. In this square, when $P_{1 S}$ and $P_{1 N} / \beta$ are larger, strategic customers may select regions $B$ or $F$, and make the same decision except nodes $a$ or $b$, which are elaborated in Table 1 . Region $D$ occupies the top left corner of the square, and within this region only node $\mathrm{b}$ is available to strategic customers; i.e., if the WTP is less than $b$, they should leave the market, otherwise they should buy products during the normal sales period via the retail channel. Region $C$ occupies the bottom right corner of the square, in which the strategic customers have the four nodes $a, e, f$ and $d$ and their detailed choices are elaborated in Table 1. Outside the square, when $P_{1 S}$ and $P_{1 N} / \beta$ are greater, the strategic customer choices are represented by regions $A$ and $E$, both of which indicate the same decision except nodes $a$ or $b$. With regards to the top left and bottom right corners of the square, the choices of strategic customers outside the square are the same as those inside it. 


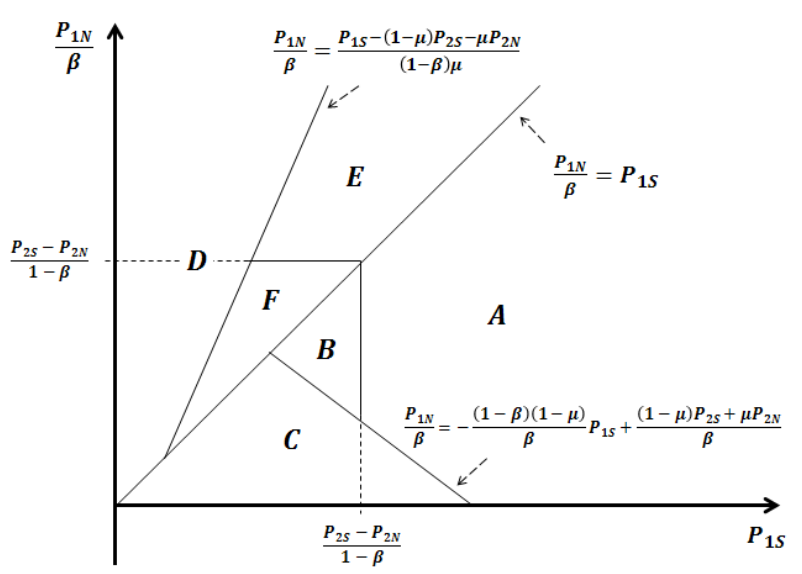

Figure 5. Choices of Strategic Customers are Expressed Through a Coordinate System

This model has parameters $\beta$ and $\mu$. Increasing $\beta$ indicates increasing satisfaction of strategic customers with the quality of products sold via the electronic channel. Meanwhile, increasing $\mu$ indicates increasing interest of strategic customers in the electronic channel during a discount sale period. We discuss the changes of strategic customer choices when these two parameters increase.

Proposition 1. As $\beta$ increases, regions $C$ and $F$ grow while regions $A$ and $D$ shrink, and the square area increases.

Proof. The detailed process is illustrated by Figure 6 . When the value of $\beta$ is increasing, straight line $P_{1 S}=\left(P_{2 S}-P_{2 N}\right) /(1-\beta)$ moves right and straight line $P_{1 N} / \beta=\left(P_{2 S}-P_{2 N}\right) /(1-\beta)$ increases, so the square area grows. However, larger $\beta$ leads to flattening of the straight line of $P_{1 N} / \beta=-(1-\beta)(1-\mu) P_{1 S} / \beta+$ $\left((1-\mu) P_{2 S}+\mu P_{2 N}\right) / \beta$, as well as a steepening of the straight line of $P_{1 N} / \beta=$ $\left(P_{1 S}-(1-\mu) P_{2 S}-\mu P_{2 N}\right) /((1-\beta) \mu)$. Therefore, the likelihood that strategic customers will select regions $C$ and $F$ increases, while the likelihood they will select regions $A$ and $D$ decreases. It is impossible to determine the changes in regions $B$ and $E$.

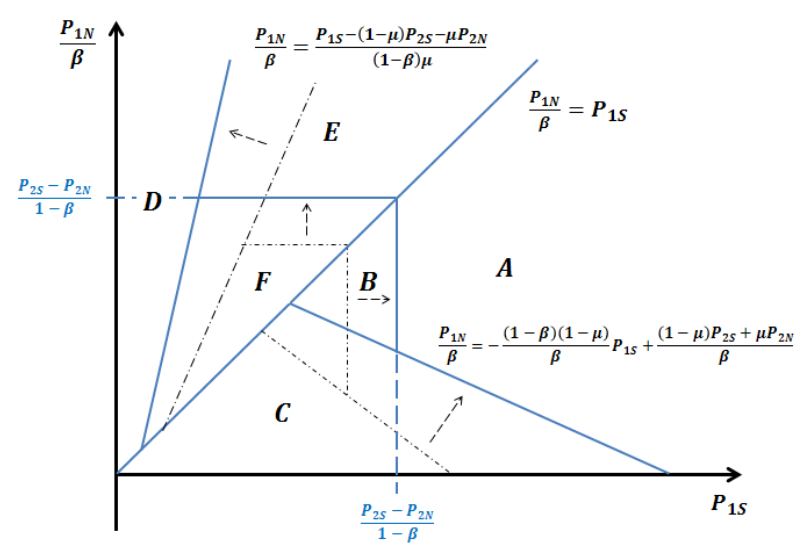

Figure 6. Changes of Strategic Customer Choices when $\beta$ is Increasing

Proposition 2. As the value of $\mu$ increases, regions $C$ and $D$ grow while regions $A, B$, $E$ and $F$ shrink.

Proof. The derived process is shown in Figure 7. When the value of $\mu$ is increasing, the straight line $P_{1 N} / \beta=-(1-\beta)(1-\mu) P_{1 S} / \beta+\left((1-\mu) P_{2 S}+\mu P_{2 N}\right) / \beta$ is relatively flat, and the slope of straight 
$P_{1 N} / \beta=\left(P_{1 S}-(1-\mu) P_{2 S}-\mu P_{2 N}\right) /((1-\beta) \mu)$ also tends smaller. Consequently, regions $C$ and $D$ grow in area while regions $A, B, E$ and $F$ shrink, i.e., strategic customers have more chances to select types $C$ and $D$.

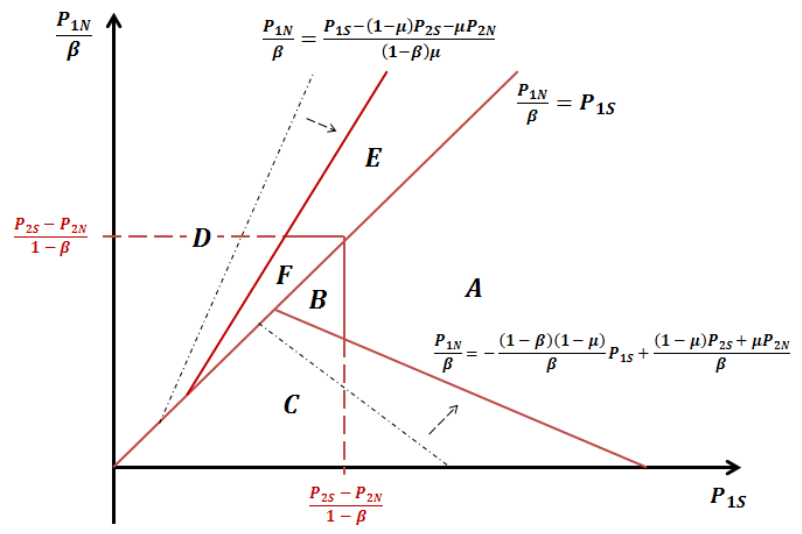

Figure 7. Changes of Strategic Customer Choices with Increasing $\mu$

\subsection{Equilibrium Analysis of Manufacturer and Retailer}

The above analysis of the choices of strategic customers reveals that different combinations of $a, b, c, d, e$ and $\mathrm{f}$ result in different choices. We discuss the equilibrium of manufacturer and retailer in relation to type $C$ in detail because this situation is the most complicated.

Supposing the demand function is $q_{i j}=x-P_{i j}$, we get the following results. In the normal sale period, the number of strategic customers that choose to purchase via the electronic channel is $Q_{1 N}=\int_{a}^{e} x-P_{1 N} d x=(e-a)\left(\frac{e+a}{2}-P_{1 N}\right)$, while the number that choose to purchase via the retail channel is $Q_{1 S}=\int_{d}^{\bar{X}} x-P_{1 S} d x=(\bar{X}-d)\left(\frac{\bar{X}+d}{2}-P_{1 S}\right)$. Therefore, the total number of customers who purchase during the first sale period is $Q_{1}=Q_{1 N}+Q_{1 S}$. Meanwhile, in the discount sale period, the number of strategic customers who choose to purchase via the electronic channel is $Q_{2 N}=\int_{e}^{f} x-P_{2 N} d x=$ $(f-e)\left(\frac{f+e}{2}-P_{2 N}\right)$, while the number who choose to purchase via the retail channel is $Q_{2 S}=\int_{f}^{d} x-P_{2 S} d x=(d-f)\left(\frac{d+f}{2}-P_{2 S}\right)$. The total number of customers who choose to purchase during the discount sale period thus is $Q_{2}=Q_{2 N}+Q_{2 S}$.

Our research uses the Stackelberg model. The manufacturer thus is dominant in the market and determines the price first, with the retailer then follows with their own pricing. The total profit function of the retailer is:

$$
\begin{aligned}
\Pi_{R} & =\Pi_{1 R}+\Pi_{2 R}=Q_{1 S}\left(P_{1 S}-W\right)+Q_{2 S}\left(P_{2 S}-W\right) \\
& =(\bar{X}-d)\left(\frac{\bar{X}+d}{2}-P_{1 S}\right)\left(P_{1 S}-W\right)+(d-f)\left(\frac{d+f}{2}-P_{2 S}\right)\left(P_{2 S}-W\right)
\end{aligned}
$$

Meanwhile, the profit function of the manufacturer is:

$$
\begin{aligned}
& \Pi_{M}=\Pi_{1 M}+\Pi_{2 M}=Q_{1 S}(W-\bar{C})+Q_{1 N}\left(P_{1 N}-\bar{C}\right)+Q_{2 S}(W-\bar{C})+Q_{2 N}\left(P_{2 N}-\bar{C}\right) \\
& \quad=(\bar{X}-d)\left(\frac{\bar{X}+d}{2}-P_{1 S}\right)(W-\bar{C})+(e-a)\left(\frac{e+a}{2}-P_{1 N}\right)\left(P_{1 N}-\bar{C}\right)+(d- \\
& f)\left(\frac{d+f}{2}-P_{2 S}\right)(W-\bar{C})+(f-e)\left(\frac{f+e}{2}-P_{2 N}\right)\left(P_{2 N}-\bar{C}\right)
\end{aligned}
$$

First, we maximize the retail profit according to the Stackelberg model, which yields several formulae as shown below. Appendix A shows the detailed solution procedure.

$$
P_{1 S}=\frac{W}{2}+\frac{\bar{x}+d}{4}, P_{2 S}=\frac{W}{2}+\frac{d+f}{4}
$$


We then analyze the profit function of the manufacturer. The result of maximizing (3) based on (4) shows the best strategy for the manufacturer.

$\max \Pi_{M}\left(P_{1 N}, P_{2 N}, W\right)$

$$
\begin{aligned}
\text { s.t. } & P_{1 S}=\frac{W}{2}+\frac{\bar{X}+d}{4} \\
P_{2 S} & =\frac{W}{2}+\frac{d+f}{4}
\end{aligned}
$$

Proposition 3. The optimal pricing of the manufacturer:

$$
\left\{\begin{array}{l}
W^{*}=\frac{\bar{C}}{2}+\frac{\bar{X}+f}{4} \\
P_{1 N}^{*}=\frac{\bar{C}}{2}+\frac{e+a}{4} \\
P_{2 N}^{*}=\frac{\bar{C}}{2}+\frac{f+e}{4}
\end{array}\right.
$$

Putting (6) into (4) obtains the optimal retail pricing as shown in the following functions:

$$
P_{1 S}^{*}=\frac{\bar{C}}{4}+\frac{3 \bar{X}+2 d+f}{8}, \quad P_{2 S}^{*}=\frac{\bar{C}}{4}+\frac{\bar{X}+2 d+3 f}{8}
$$

Proof. For the detailed solution, please see Appendix B.

Proposition 3 shows the Stackelberg equilibrium of manufacture and retailer when the choice type of strategic customers is $C$. To maximize their benefit, the manufacturer decides to set the price during the normal sale period below that during the discount sale period, i.e., $P_{1 N}<P_{2 N}$, while both these prices are also below the wholesale price $W$. Consequently, if the manufacturer can predict the choices of strategic customers, they can cut prices in their own electronic channel to below the wholesale price and can raise the price during the discount sale period. This enables the manufacturer to take customers from the retailer and exceed the expectations of strategic customers, who think the discount price should be below the normal price. In the retail channel, the retailer setting the price meets the expectations of strategic customers, i.e., $P_{1 S}>P_{2 S}$.

\begin{tabular}{|c|c|c|}
\hline & Manufacturer & Retailer \\
\hline$A$ & $W^{A}=\frac{\bar{C}}{2}+\frac{\bar{X}+a}{4}$ & $P_{1 S}^{A}=\frac{\bar{C}}{4}+\frac{3 \bar{X}+a+2 d}{8} ; P_{2 S}^{A}=\frac{\bar{C}}{4}+\frac{\bar{X}+3 a+2 d}{8}$ \\
\hline$B$ & $W^{B}=\frac{\bar{C}}{2}+\frac{\bar{X}+f}{4} ; P_{2 N}^{B}=\frac{\bar{C}}{2}+\frac{f+a}{4}$ & $P_{1 S}^{B}=\frac{\bar{C}}{4}+\frac{3 \bar{X}+2 d+f}{8} ; P_{2 S}^{B}=\frac{\bar{C}}{4}+\frac{\bar{X}+2 d+3 f}{8}$ \\
\hline C & $\begin{array}{c}W^{C}=\frac{\bar{C}}{2}+\frac{\bar{X}+f}{4} ; P_{1 N}^{C}=\frac{\bar{C}}{2}+\frac{e+a}{4} \\
P_{2 N}^{C}=\frac{\bar{C}}{2}+\frac{f+e}{4}\end{array}$ & $P_{1 S}^{C}=\frac{\bar{C}}{4}+\frac{3 \bar{X}+2 d+f}{8} ; P_{2 S}^{C}=\frac{\bar{C}}{4}+\frac{\bar{x}+2 d+3 f}{8}$ \\
\hline$D$ & $W^{D}=\frac{\bar{c}}{2}+\frac{\bar{X}+b}{4}$ & $P_{1 S}^{D}=\frac{\bar{c}}{4}+\frac{3 \bar{X}+3 b}{8}$ \\
\hline$E$ & $W^{E}=\frac{\bar{C}}{2}+\frac{\bar{X}+b}{4}$ & $P_{1 S}^{E}=\frac{\bar{C}}{4}+\frac{3 \bar{X}+2 d+b}{8} ; P_{2 S}^{E}=\frac{\bar{C}}{4}+\frac{\bar{X}+2 d+3 b}{8}$ \\
\hline$F$ & $W^{F}=\frac{\bar{C}}{2}+\frac{\bar{X}+f}{4} ; P_{2 N}^{F}=\frac{\bar{C}}{2}+\frac{f+b}{4}$ & $P_{1 S}^{F}=\frac{\bar{C}}{4}+\frac{3 \bar{X}+2 d+f}{8} ; P_{2 S}^{F}=\frac{\bar{C}}{4}+\frac{\bar{X}+2 d+3 f}{8}$ \\
\hline
\end{tabular}

The derivation process of other types resembles that described above. All equilibrium results are listed in Table 2.

Table 2. Equilibrium Results of Manufacturer and Retailer 
The strategic customers have six different types, but types $A$ and $E$ are similar, as are types $B$ and $F$. From the perspective of the manufacturer and retailer, strategic customers have four different choices, which depend on the parameters. First, in choice type $A^{\prime}$, which includes $A$ and $E$, strategic customers only purchase via the retail channel, and the electronic channel becomes a mechanism for product display with zero sales. Second, in type $B^{\prime}$, which includes $B$ and $F$, the strategic customers purchase via both the electronic and retail channels during the discount sale period, and during the normal sale period the electronic channel has no sales. Third, in type $C$ every sale channel has strategic customers to buy. Fourth, in type $D$, the strategic customers only buy products during the normal sale period via the retail channel, and all other channels have zero sales. Table 3 shows the maximum profit of the manufacturer and retailer according to the Stackelberg model.

Table 3. The Optimal Profit of Manufacturer and Retailer in the Stackelberg Model

\begin{tabular}{c|c|c}
\hline & Manufacturer & Retailer \\
\hline$A^{\prime}$ & $\Pi_{M}^{A}=2(\bar{X}-a)\left(\frac{\bar{X}+a-2 \bar{C}}{8}\right)^{2}$ & $\Pi_{R}^{A}=(d-a)\left(\frac{a+2 d-2 \bar{C}-\bar{X}}{8}\right)^{2}+$ \\
\hline$B^{\prime}$ & $\Pi_{M}^{B}=(f-a)\left(\frac{a+f-2 \bar{C}}{4}\right)^{2}+2(\bar{X}-a)\left(\frac{\bar{X}+a-2 \bar{C}}{8}\right)^{2}$ & $\Pi_{R}^{B}=(d-f)\left(\frac{f+2 d-2 \bar{C}-\bar{X}}{8}\right)^{2}+$ \\
\hline$C$ & $\Pi_{M}^{C}=(e-a)\left(\frac{a+e-2 \bar{C}}{4}\right)^{2}+(f-e)\left(\frac{e+f-2 \bar{C}}{4}\right)^{2}+$ & $\Pi_{R}^{C}=(d-f)\left(\frac{f d-f-2 \bar{C}+\bar{X}}{8}\right)^{2}$ \\
\hline & $2(\bar{X}-f)\left(\frac{f+\bar{X}-2 \bar{C}}{8}\right)^{2}$ & $(\bar{X}-d)\left(\frac{2 d-f-2 \bar{C}-\bar{X}}{8}\right)^{2}+$ \\
\hline$D$ & $\Pi_{M}^{D}=2(\bar{X}-b)\left(\frac{\bar{X}+b-2 \bar{C}}{8}\right)^{2}$ & $\Pi_{R}^{D}=(\bar{X}-b)\left(\frac{\bar{X}+b-2 \bar{C}}{8}\right)^{2}$ \\
\hline
\end{tabular}

\section{Numerical Analysis}

Each of the four types of strategic customer choices has associated parameters. The following analyzes how these parameters affect the profit functions of the manufacturer and retailer. Choice type $A^{\prime}$ has the two parameters $a$ and $d$. For choice type $B^{\prime}$ the three associated parameters $a$, f and $\mathrm{d}$ influence the profit functions. Choice type $C$ involves the most complex situation, with four associated parameters, $a, e, f$ and $d$. Finally, choice type $D$ has only parameter $b$ associated with it; i.e., the strategic customers either buy products during the normal sale period via the retail channel or leave the market.

We set $P_{1 S}=0.95, P_{1 N}=0.8, P_{2 S}=0.78, P_{2 N}=0.7, \mu=0.5, \beta=0.9, \bar{X}=5$ and $\bar{C}=0.45$, and these assumptions meet type $A^{\prime}$. According to formula (1), we analyze how parameters a and $d$ influence manufacturer and retailer profit. As parameter a increases, manufacturer profit first increases then declines, while retailer profit declines. Maximum profit for the manufacturer occurs when a is around 2. The manufacturer should not only consider its own profit, but also the benefit of the retailer. In interval $[0,2]$, manufacturer profit peaks while retailer profit is higher than in other intervals. Therefore, the manufacturer strives to ensure $a$ is less than 2 . As parameter $d$ is increasing, manufacturer 
profit remains unchanged while retailer profit first increases then decreases. Retailer profit peaks when $d$ is around 3.3. Figure 6 illustrates the above analysis.

Choice type $B^{\prime}$ is associated with the three parameters $a, f$ and $d$. Suppose $\beta=0.95$, $\bar{X}=10$ and other settings are the same as type $A^{\prime}$. When parameter $a$ is increasing, manufacturer profit is always decreasing, while retailer profit remains unchanged. Manufacturer profit is maximized when $a$ is near zero. Moreover, manufacturer profit increases with parameter $f$, while retailer profit decreases. Finally, manufacturer profit remains unchanged when parameter $d$ increases, while retailer profit first climbs and then falls.

The setting $P_{1 S}=0.95, P_{1 N}=0.72, P_{2 S}=0.78, P_{2 N}=0.7, \mu=0.1, \beta=0.95$, $\bar{X}=40$ and $\bar{C}=0.45$ represents numerical values that satisfy choice type $C$. The changes of profit with parameters $a, f$ and $d$ are similar to type $B^{\prime}$. As parameter $e$ increases, manufacturer profit remains constant, while retailer profit first increases and then decreases. The optimal value of $e$ for the retailer thus is around 21, where the retailer can require the maximum profit.

For choice type $D$, reset $\mu=0.8$ and $\beta=0.5$, while other numerical values remain the same as for choice type $A^{\prime}$. The manufacturer and retailer profit first increase and then decrease simultaneously. The profit of the manufacturer is twice that of the retailer, and $b$ of around 2 allows the manufacturer and retailer to maximize their profit.

Proposition 4. ( i ) Type $A^{\prime}$. The manufacturer and retailer need to negotiate the value of parameter $\mathrm{a}$, which lies somewhere between zero and the value that maximizes manufacturer profit. Additionally, the manufacturer must consider parameter $\mathrm{d}$ from the perspective of the retailer. The value of $d$ should be near that which maximizes the profit of the retailer.

(ii) Type B'. When setting parameter a, the manufacturer may ignore the retailer and simply set a value closer to zero, which is better for themselves. However, the manufacturer needs to consider the perspective of the retailer to estimate parameter $\mathrm{d}$, which is set near the value that maximizes retailer profit. The manufacturer should negotiate the value of parameter $f$ with the retailer, and it should be between a and $d$.

(iii) Type C. The manufacturer can only consider its own profit function and the value of parameter a should approach zero. For parameters e or $d$, the manufacturer may ignore their own benefit and only consider the profit of the retailer. The values of e or $d$ thus are set near the points that maximize retailer profit function. The manufacturer should discuss the value of parameter $f$ with the retailer, because in this case the manufacturer and retailer profit functions have opposite trends. However, the value of $f$ should be between e and $\mathrm{d}$.

(iv) Type D. Both the manufacturer and retailer expect the value of parameter $b$ to be near the point that maximizes their profit, since their profit functions share a common trend.

Proof. Figure 8-11 explains the conclusion in detail. 

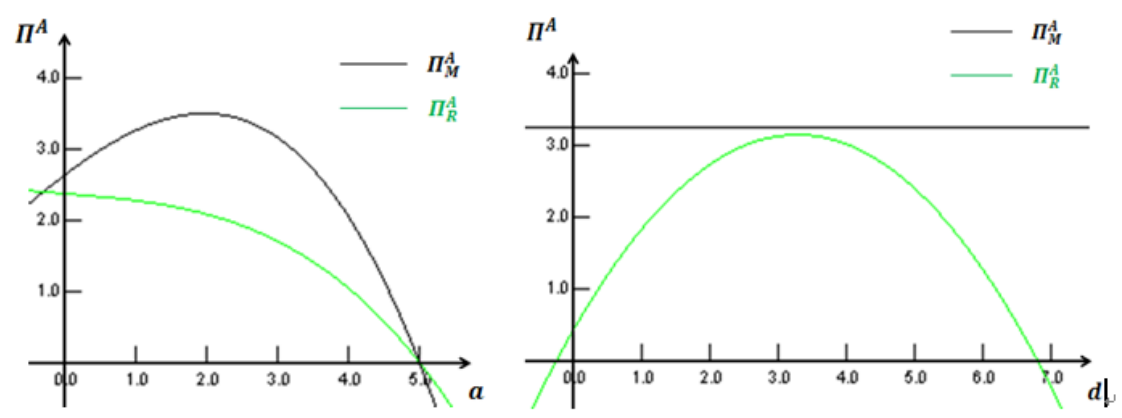

Figure 8. Change of Profit with Increasing $a$ or $d$ in Choice Type $A^{\prime}$
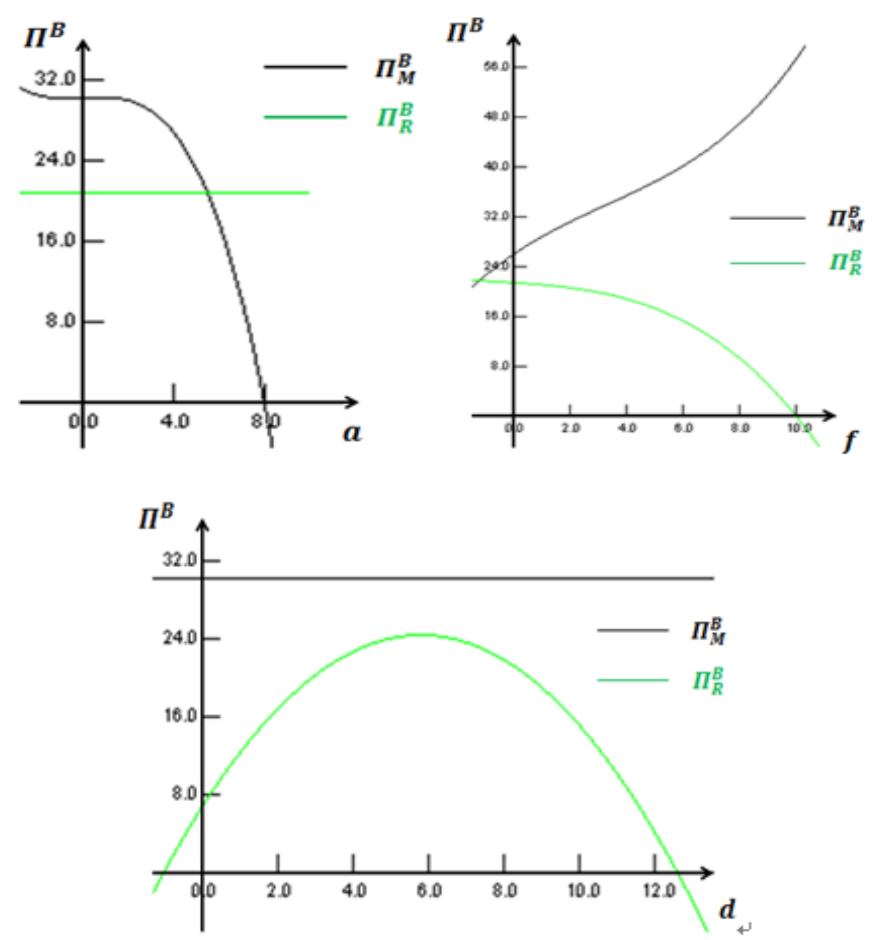

Figure 9. Change of profit with increasing $a, f$ and $d$ in type $B^{\prime}$ 

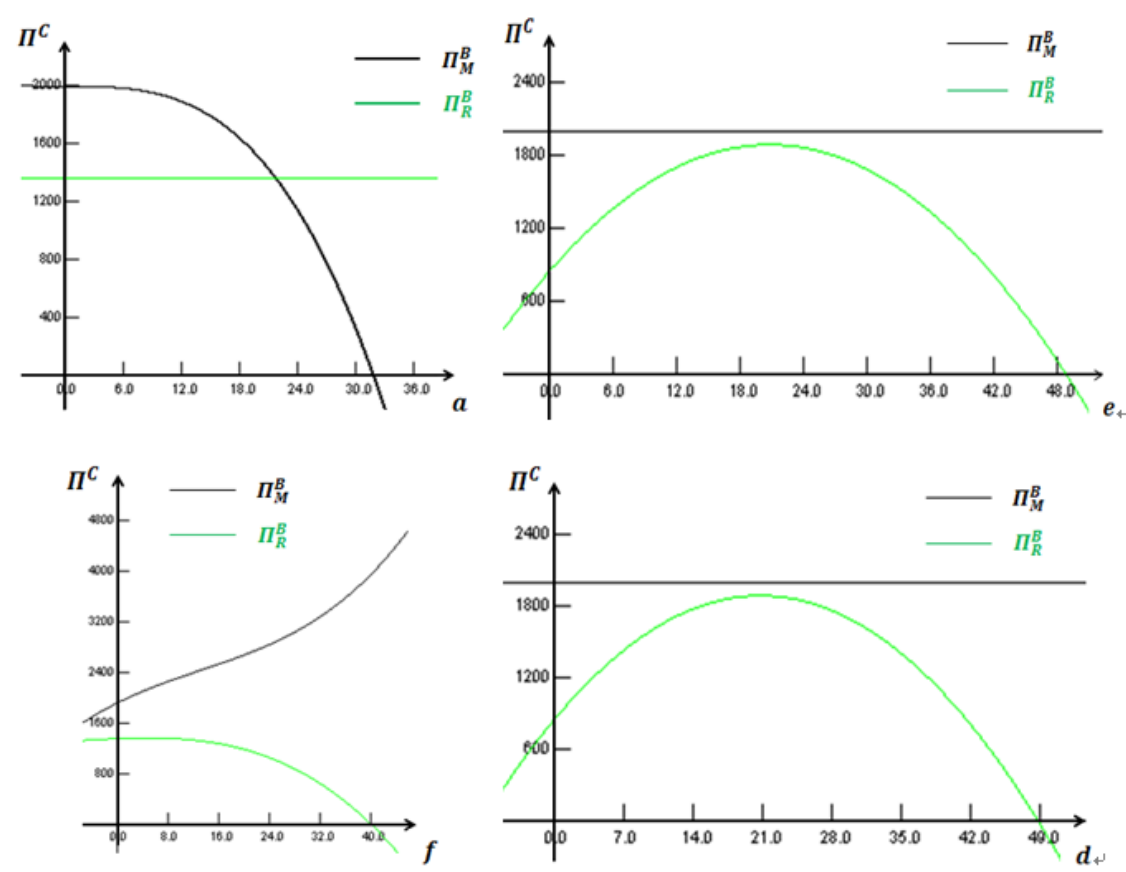

Figure 10. Change of Profit with Increasing $a, e, f$ and $d$ in Choice Type $C$

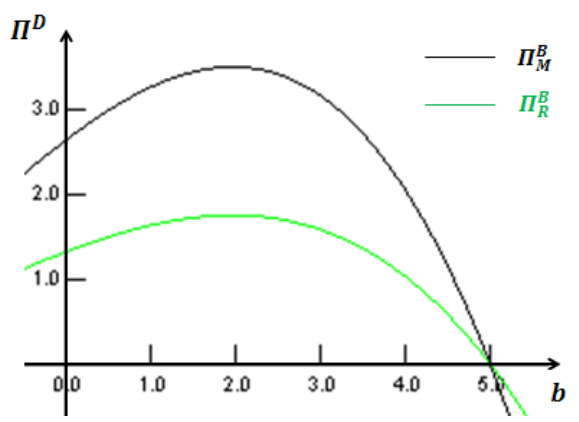

Figure 11. Change of Profit with Increasing b in Choice Type D

\section{Conclusions and Managerial Implications}

E-commerce drives the development of electronic channel. Many manufacturers and retailers have adopted this sales method, which offers customers more purchase selections. Simultaneously, customers have become increasingly shrewd, and have learned to wait rather than buy immediately. Specifically, customers have evolved strategic behaviors; i.e., they have become strategic customers. This paper analyzes the issues involved in how strategic customers select their purchase channels and times, and how manufacturers and retailers react to these strategic behaviors.

Based on the previous literature, we divided the transaction period into normal and discount sale periods. In each period, strategic customers act to maximize consumer surplus. The choices of strategic customers are broken down into six types according to different combinations of parameters. The likelihood of strategic customers leaving the market increases with decreasing $\bar{X}$. Meanwhile, higher $\bar{X}$ increases the likelihood of strategic customers buying during the normal sales period via the retail channel. We also discussed how changes in $\beta$ affect strategic customer choices. Specifically, as $\beta$ increases, regions $C$ and $F$ grow while regions $A$ and $D$ shrink, and the square area also grows. We also discuss the change of parameter $\mu$. Specifically, as $\mu$ increases, regions $C$ and $D$ grow while regions $A, B, E$ and $F$ shrink. We then analyzed the equilibrium between 
manufacturer and retailer using the Stackelberg model, in which the manufacturer leads while the retailer follows. We found that the manufacturer considers retailer profit in addition to its own benefit. The manufacturer and retailer may not differentiate the nuance between $A$ and $E$, or $B$ and $F$. The nuance is caused by parameters $\beta$ and $\mu$, which are decided by the strategic customers, so the manufacturer and retailer do not know the value. From the perspective of the manufacturer and retailer, types $A$ and $E$ are similar, as are types $B$ and $F$. Therefore, the six different kinds of strategic customer choices can be classified into four types $A^{\prime}, B^{\prime}, C$ and $D$. For Type $C$, where the strategic customers can be distributed in $1 S, 1 N, 2 S$ and $2 N$, the manufacturer sets the prices as $W^{C}=\frac{\bar{C}}{2}+\frac{\bar{X}+f}{4}$, $P_{1 N}^{C}=\frac{\bar{C}}{2}+\frac{e+a}{4}$ and $P_{2 N}^{C}=\frac{\bar{C}}{2}+\frac{f+e}{4}$, while the retailer sets the retail channel prices as $P_{1 S}^{C}=\frac{\bar{C}}{4}+\frac{3 \bar{X}+2 d+f}{8}$ and $P_{2 S}^{C}=\frac{\bar{C}}{4}+\frac{\bar{X}+2 d+3 f}{8}$. The optimal profit of the manufacturer is $\Pi_{M}^{C}=(e-a)\left(\frac{a+e-2 \bar{C}}{4}\right)^{2}+(f-e)\left(\frac{e+f-2 \bar{C}}{4}\right)^{2}+2(\bar{X}-f)\left(\frac{f+\bar{X}-2 \bar{C}}{8}\right)^{2}$, while that of the retailer is $\Pi_{R}^{C}=(d-f)\left(\frac{f+2 d-2 \bar{C}-\bar{X}}{8}\right)^{2}+(\bar{X}-d)\left(\frac{2 d-f-2 \bar{C}+\bar{X}}{8}\right)^{2}$. The equilibrium results of other types are shown in Table 2-3. Finally, numerical analysis is applied to study how the parameters influence the profit functions. We find that parameter a is close to zero, which is better for both the manufacturer and the retailer, regardless of type. Parameter $b$ only appears in type $D$, and both the manufacturer and retailer expect it to have a value near that which maximizes their respective profits. Parameter $d$ is set to near the value that maximizes retailer profit, because its value may not affect manufacturer profit and only considers the retailer profit. Parameter $e$ is presented in type $C$, and its trend is similar to that of parameter $d$. The value of parameter $e$ is near that which maximizes retailer profit. Regarding parameter $f$, since manufacturer and retailer functions simultaneously move in opposite directions, the manufacturer should negotiate its value with the retailer. Discussing the parameters helps both the manufacturer and retailer, and allows them to take appropriate measures to improve their interests, and reduce losses from the behavior of strategic customers.

We identify three important managerial implications that can help the manufacturer and retailer better understand strategic customers and develop strategies to mitigate their influence. First, the manufacturer and retailer can strengthen advertising of new products to increase the WTP of strategic customers even before products come on the market. Regardless of strategic customer choices, strategic customers may leave the market if WTP is low and near zero. The manufacturer and retailer thus must adopt measures to attract strategic customers and reduce the number that leave the market. For example, new products can be advertised alongside existing products, limited quantity offers can be made, and so on. These measures can grow the interest of strategic customers in new products, and reduce the likelihood of them leaving the market.

Second, the manufacturer can set electronic channel prices at below wholesale prices to maximize interest, such as by setting $W^{B}=\frac{\bar{C}}{2}+\frac{\bar{X}+f}{4}>P_{2 N}^{B}=\frac{\bar{C}}{2}+\frac{f+a}{4}$ in type $B$. Furthermore, the discount price can be set to exceed the normal price. Such price setting exceeds the expectations of strategic customers; for example $P_{1 N}^{C}=\frac{\bar{C}}{2}+\frac{e+a}{4}<P_{2 N}^{C}=\frac{\bar{C}}{2}+$ $\frac{f+e}{4}$ in type $C$. The manufacturer can apply these strategies to increase their profit under the single game condition. Under the repeated game condition, the manufacturer cannot take this action, because strategic customers have strong learning ability and will never trust the discount price is lower than the normal price.

Third, the manufacturer can improve their profits by decreasing parameter $a$. In the Stackelberg model, the manufacturer and retailer form a close-knit community of 
interests, in which the manufacturer plays the dominant role. This arrangement empowers the manufacturer to decrease a to increase their profits. In type $A^{\prime}$, the value of $a$ is closer to the extreme point, the manufacturer may require more profits. The manufacturer also considers the retailer benefit, so the value is allowed between zero and whatever value maximizes manufacturer benefit. In types $B^{\prime}$ and $C$, a of around zero is favorable to the manufacturer. The manufacturer thus can set the value to near zero regardless of type.

In this paper, we assume all the customers are strategic. However, the customers have individual differences, such as in age, education, experience and so on. The result is that not all customers may be strategic in real markets, and this field deserves further study. Our study assumes the manufacturer controls the electronic channel, but in the real world the retailer can also exert control. Ownership of the electronic channel affects the choices of strategic customers. Therefore, the issue of how different dual channel structures influence strategic behaviors should be researched. Besides, products offered via electronic channel may differ from those offered via retail channel. Facing product heterogeneity, strategic customers must estimate differences and decide how to make their purchase decisions. This is an important issue that deserves further discussion.

\section{Acknowledgements}

This research was supported by the National Natural Science Foundation of China (NSFC) (Project Nos. 71371159 and 71201138), the National Ministry of Education of China (Humanities and Social Science Project No. 12YJC63026) and the Fujian Provincial Natural Science Foundation (Project No. 2012J01304).

\section{Appendix A}

The retailer should decide the retail channel sales prices, i.e., $P_{1 S}$ and $P_{2 S}$. To maximize total retailer profit, we need to take the first-order partial derivatives of (2) with respect to $P_{1 S}$ and $P_{2 S}$ :

$$
\left\{\begin{array}{l}
\frac{\partial \Pi_{R}}{\partial P_{1 S}}=(\bar{X}-d)\left(-P_{1 S}+W+\frac{\bar{X}+d}{2}-P_{1 S}\right)=0 \\
\frac{\partial \Pi_{R}}{\partial P_{2 S}}=(d-f)\left(-P_{2 S}+W+\frac{d+f}{2}-P_{2 S}\right)=0
\end{array}\right.
$$

The solution to the equation is as follows and we can get the same results as (4).

$$
\left\{\begin{array}{l}
P_{1 S}=\frac{W}{2}+\frac{\bar{X}+d}{4} \\
P_{2 S}=\frac{W}{2}+\frac{d+f}{4}
\end{array} .\right.
$$

\section{Appendix B}

The manufacturer must determine the wholesale price $W$, and the electronic channel sales prices. To find the optimal solution, construct the Lagrangian function, and set the first-order partial derivatives with respect to $P_{1 N}, P_{2 N}$ and $W$ as zero:

$$
\begin{aligned}
& \max L\left(W, P_{1 N}, P_{2 N}, \lambda, \gamma\right)= \\
& \Pi_{M}\left(P_{1 N}, P_{2 N}, W\right)+\lambda\left(P_{1 S}-\frac{W}{2}-\frac{\bar{X}+d}{4}\right)+\gamma\left(P_{2 S}-\frac{W}{2}-\frac{d+f}{4}\right)
\end{aligned}
$$




$$
\left\{\begin{array}{l}
\frac{\partial \Pi_{M}}{\partial W}=-\frac{(\bar{X}-f)(W-\bar{C})-\bar{X}^{2}+\bar{f}^{2}}{2}-(\bar{X}-d) P_{1 S}-(d-f) P_{2 S}=0 \\
\frac{\partial \Pi_{M}}{\partial P_{1 N}}=(e-a)\left(\frac{e+a}{2}+\bar{C}-2 P_{1 N}\right)=0 \\
\frac{\partial \Pi_{M}}{\partial P_{2 N}}=(f-e)\left(\frac{f+e}{2}+\bar{C}-2 P_{2 N}\right)=0 \\
\frac{\partial \Pi_{M}}{\partial \lambda}=P_{1 S}-\frac{W}{2}-\frac{\bar{X}+d}{4}=0 \\
\frac{\partial \Pi_{M}}{\partial \gamma}=P_{2 S}-\frac{W}{2}-\frac{d+f}{4}=0
\end{array}\right.
$$

Calculating the second and the third equations yields the functions: $P_{1 N}^{*}=\frac{\bar{C}}{2}+\frac{e+a}{4}$, $P_{2 N}^{*}=\frac{\bar{C}}{2}+\frac{f+e}{4}$. The fourth and fifth equations are then put into the first equation, and it is deduced that $W^{*}=\frac{\bar{C}}{2}+\frac{\bar{X}+f}{4}$.

\section{References}

[1]. S. R. Croom, "The impact of e-business on supply chain management: an empirical study of key developments", International Journal of Operations and Production Management, vol. 25, no. 1, (2005).

[2]. K. L. Webb and J.E. Hogan, "Hybrid channel conflict: causes and effects on channel performance", Journal of Business \& Industrial Marketing, vol. 17, no. 5, (2002).

[3]. W. Y. K. Chiang, D. Chhajed and J. D. Hess, "Direct marketing, indirect profits: a strategic analysis of dual-channel supply-chain design”, Management Science, vol. 49, no. 1, (2003).

[4]. J. Davis, "Manufacturers are testing the web for direct sales: some are finding success", Infomation World, vol. 35, no. 5, (2001).

[5]. D. Hardman, S. Harper and A. Notaney, "Keeping inventory-And profits-Off the discount rack", White paper, Booz Allen, Hamilton Inc., (2007).

[6]. X. Su, "Intertemporal pricing with strategic customer behavior", Management Science, vol. 53, no. 5, (2007).

[7]. H. Nair, "Intertemporal price discrimination with forward-looking consumers: Application to the US market for console video-games", Quantitative Marketing and Economics, vol. 5, no. 3, (2007).

[8]. G.G. Cai, "Channel selection and coordination in dual-channel supply chains", Journal of Retailing, vol. 86, no. $1,(\mathbf{2 0 1 0})$

[9]. S. Y. Park and H. T. Keh, "Modelling hybrid distribution channels: a game-theoretic analysis", Journal of Retailing and Consumer Services, vol. 10, no. 3, (2003).

[10].A. Arya, B. Mittendorf and D. E. Sappington, "The Bright Side of Supplier Encroachment", Marketing Science, vol. 26, no. 5, (2007).

[11].D.Q. Yao and J. J. Liu, "Competitive pricing of mixed retail and e-tail distribution channels", Omega, vol. 33, no. 3, (2005).

[12].R. Yan and Z. Pei, "Retail services and firm profit in a dual-channel market", Journal of Retailing and Consumer Services, vol. 16, no. 4, (2009).

[13].S. H. Chun, B. D. Rhee, S. Y. Park and J. C. Kim, "Emerging dual channel system and manufacturer's direct retail channel strategy", International Review of Economics and Finance, vol. 20, no. 4, (2011).

[14].A. A. Tsay and N. Agrawal, "Channel Conflict and Coordination in the E-Commerce Age", Production and Operations Management, vol. 13, no. 1, (2004).

[15].F. Zettlemeyer, "Expanding to the Internet: pricing and communications strategies when firms compete on multiple channels", Journal of Marketing Research, vol. 37, no. 3, (2000).

[16].K. Cattani, W. Gilland, H.S. Heese and J. Swaminathan, "Boiling frogs: pricing strategies for a manufacturer adding a direct channel that competes with the traditional channel", Production and Operations Management, vol. 15, no. 1, (2006).

[17].S. K. Mukhopadhyay, X. Zhu and X. Yue, "Optimal contract design for mixed channels under information asymmetry", Production and Operations Management, vol. 17, no. 6, (2008).

[18].R. Yan and S. Ghose, "Forecast information and traditional retailer performance in a dual-channel competitive market", Journal of Business Research, vol. 63, no. 1, (2010).

[19].W. Xing, C. Y. Wang, Q.H. Zhao and G. W. Hua, "Impact of fairness on strategies in dual-channel supply chain", Systems Engineering-Theory and Practice, vol. 31, no. 7, (2011).

[20].J. Chen, H. Zhang and Y. Sun, "Implementing coordination contracts in a manufacturer Stackelberg dual-channel supply chain", Omega, vol. 40, no. 5, (2012).

[21].R. H. Coase, "Durability and monopoly", Journal of Law and Economics, vol. 15, no. 1, (1972). 
[22].D. Besanko and W. L. Winston, "Optimal price skimming by a monopolist facing rational consumers", Management Science, vol. 36, no. 5, (1990).

[23].G. P. Cachon and R. Swinney, "Purchasing, pricing, and quick response in the presence of strategic consumers", Management Science, vol. 55, no. 3, (2009).

[24].G. M. Lai, L. G. Debo and K. Sycara, "Buy now and match later: the impact of posterior price matching on profit with strategic consumers", Manufacturing and Service Operation Management, vol. 12, no. 1, (2010).

[25].X. Su and F. Zhang, "Strategic customer behavior, commitment, and supply chain performance", Management Science, vol. 54, no. 10, (2008).

[26].X. Su and F. Zhang, "On the value of commitment and availability guarantees when selling to strategic consumers", Management Science, vol. 55, no. 5, (2009).

[27].Y. Aviv and A. Pazgal, "Optimal pricing of seasonal products in the presence of forward-looking consumers", Manufacturing and Service Operation Management, vol. 10, no. 3, (2008).

[28].G. P. Cachon and R. Swinney, "The value of fast fashion: Quick response, enhanced design, and strategic consumer behavior", Management Science, vol. 57, no. 4, (2011).

[29].X. Su, "Optimal pricing with speculators and strategic consumers", Management Science, vol. 56, no. 1, (2010).

[30].X. F. Liu and P. Huang, "Optimal dynamic pricing and inventory policy under strategic customers", Journal of Management Science in China, vol. 12, no. 5, (2009).

[31].G. J. Ji and G. Y. Yang, "On value of most favored customer guarantees to early purchase when selling to strategic customers", Journal of Management Science in China, vol. 13, no.7, (2010).

[32].K. Jerath, S. Netessine and S. K. Veeraraghavan, "Revenue management with strategic customers: Lastminute selling and opaque selling", Management Science, vol. 56, no. 3, (2010).

[33].Q. Liu and D. Zhang, "Dynamic pricing competition with strategic customers under vertical product differentiation", Management Science, vol. 59, no. 1, (2013). 